\title{
Nationale Grundrechte im Anwendungsbereich des Rechts der Europäischen Union
}

Die Kooperation des Grundrechtsschutzes in der Europäischen Union unter Berücksichtigung der besonderen Ausprägungen des nationalen Grundrechtsschutzes

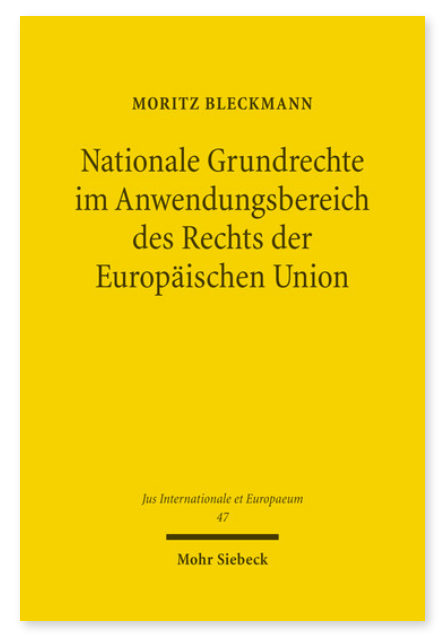

2011. XXVII, 431 Seiten. JusIntEu 47

ISBN 978-3-16-151186-8

DOI 10.1628/978-3-16-151186-8

eBook PDF 104,00€

ISBN 978-3-16-150723-6

fadengeheftete Broschur 104,00€
Der Vertrag von Lissabon hat den Grundrechtsschutz in der Europäischen Union auf eine neue vertragliche Grundlage gestellt. Die Charta der Grundrechte formalisiert die materielle Anbindung des unionsrechtlichen Grundrechtsschutzes an die EMRK. Im Hinblick auf die besonderen Ausprägungen der nationalen Grundrechtsordnungen liegt die Verantwortung für die Koordination des Grundrechtsschutzes im europäischen Mehrebenensystem jedoch unverändert in den Händen des EuGH, des EGMR und der nationalen Verfassungsgerichte. Die ersten beiden Teile dieses Buches sind der Frage gewidmet, welchen grundrechtlichen Bindungen der innerstaatliche Rechtsanwender im Anwendungsbereich des Unionsrechts unterliegt. Im dritten Teil untersucht Moritz Bleckmann, unter welchen Voraussetzungen sich der nationale Schutzstandard im Einzelfall auch im Anwendungsbereich des Unionsrechts durchsetzen kann.

Moritz Bleckmann Geboren 1979; Studium der Rechtswissenschaft in Köln und Paris; Aufbaustudium Master of Arts in European Advanced Interdisciplinary Studies am College of Europe, Campus Natolin (Warschau); 2010 Promotion; Rechtsanwalt in Berlin.

Jetzt bestellen:

https://mohrsiebeck.com/buch/nationale-grundrechte-im-anwendungsbereich-des-rechts-der-europaeischen-union9783161511868?no_cache $=1$ order@mohrsiebeck.com

Telefon: +49 (0)7071-923-17

Telefax: +49 (0)7071-51104 